\title{
ALTERAÇOEES QUANTITATIVAS DAS CÉLULAS DE PURKINJE NA MOLÉSTIA DE CHAGAS EXPERIMENTAL NO CAMUNDONGO
}

\author{
EDYMAR JARDIM *
}

Desde as primeiras descrições de Carlos Chagas sôbre a patologia da moléstia que leva o seu nome, é salientada a importância do comprometimento do sistema nervoso central. $O$ grande cientista brasileiro afirmava então, "que relativamente à freqüência das formas nervosas da tripanosomíase, possuímos numerosas observaçōes que nos autorizam a afirmar que esta do€nça, talvez, provoque, em patologia humana o maior número de afecções orgânicas do sistema nervoso central" 4 .

No entanto, a partir das publicações iniciais sôbre a moléstia de Chägas, a atenção dos estudiosos dirigiu-se para as formas cardiacas, talvez em virtude de sua maior freqüência. Dai o elevado número de trabalhos sôbre os diferentes aspectos clínicos e patológicos dessa forma da moléstia.

Por outro lado, as investigaçōes neuropatológicas são escassas, restringindo-se, em geral, à descrição de lesões observadas no sistema nervoso. Uma nova etapa das pesquisas sôbre a moléstia de Chagas foi inaugurada por Köberle que, através de investigações originais, deixou bem clara a necessidade de estudos quantitativos sistematizados para a avaliação do grau de comprometimento do sistema nervoso, de sua extensão e de sua correlação com os achados clínicos. Este investigador chamou a atenção para o fato de que a simples verificação de lesões parenquimatosas não é suficiente para o estudo da forma nervosa, mas que "o patologista deve fazer constar o grau de destruição dos neurônios mediante investigações quantitativas das distintas partes do sistema nervoso central" ".

Os estudos de Köberle e seus colaboracores, dirigidos sempre para a determinação das alterações quantitativas neuronais, vieram abrir nôvo panorama nas pesquisas sôbre a patogenia dos megas (megaesôfago, megacolo, megabexiga, etc.) e da cardiopatia chagásica.

A ampla documentação neurológica apresentada por Chagas, há 50 anos, nāo encontrou repetição. A análise da literatura especializada não confirma o elevado número de casos neurológicos previsto por Chagas em suas primeiras publicações. A casuística é, em verdade, escassa. Poderia, então, surgir a pergunta: teriam desaparecido as formas nervosas da doença? Parece-nos que não. Existe, sim, dificuldade na correlação entre os diver-

Resumo da tese de doutoramento apresentada à Faculdade de Medicina de Ribeirāo Prêto da Universidade de São Paulo.

* Professor Assistente do Departamneto de Neurologia da Faculdade de Medicina de Ribeirāo Prêto da Universidade de São Paulo (Prof. J. Armbrust-Figueiredo). 
sos aspectos clínicos e a possível etiologia chagásica; sòmente os estudos experimentais e os exames neuropatológicos de rotina poderão confirmar as suspeitas clínicas diagnósticas, permitindo que a moléstia de Chagas venha ocupar a posição de relêvo que lhe é devida dentro da Neurologia.

$O$ estudo quantitativo sistematizado dos elementos neuronais na moléstia de Chagas vem sendo realizado na Faculdade de Medicina de Ribeirão Prêto desde 1955. Nessa ocasião Köberle iniciou suas pesquisas, que vêm se desenvolvendo de maneira contínua através dos últimos anos, congregando os esforços de diferentes Serviços. Vários setores da moléstia têm sido abordados, resultando em novos e importantes esclarecimentos sôbre o problema; investigações de valor têm constituído o assunto básico de várias teses apresentadas à nossa Faculdade, e o Departamento de Patologia continua a estabelecer os alicerces da estrutura dessa nova fase da moléstia de Chagas, demonstrando que as formas nervosas são, indiscutìvelmente, "a essência da enfermidade" 6, pois as demais alterações orgânicas observadas devem ser consideradas como conseqüência da agressão inicial ao sistema nervoso, central ou periférico.

Köberle tem acentuado que êsse estudo "exige uma estreita colaboração do clínico com o patologista" 6 . Decidimo-nos, pois, estudar um pequeno item da neuropatologia chagásica, ou seja, as alterações quantitativas das células de Purkinje na moléstia de Chagas experimental no camundongo.

MATERIAL E METODOS

Utilizamos 24 camundongos albinos jovens, com idades variando entre 18 e 20 dias, de ambos os sexos, cujos pesos variaram entre 10 e 12 g. Dêsses 24 animais, 10 constituíram o grupo contrôle e 14 o grupo patológico.

Os animais do grupo normal sạ̃o representados no texto, nos gráficos e nas tabelas, pelas letras $\mathrm{CN}$ e os dr grupo patológico por $\mathrm{CP}$, seguidas pelo número de ordem.

\begin{tabular}{|c|c|c|c|c|c|}
\hline \multirow{2}{*}{ Animal } & \multicolumn{3}{|c|}{ Dias após a } & a inoculacão & \multirow[b]{2}{*}{90} \\
\hline & 50 & $6^{\circ}$ & 70 & $8^{0}$ & \\
\hline CP1 & 2 & 6 & 9 & 22 & \\
\hline CP2 & 4 & 11 & 11 & 5 & \\
\hline CP3 & 2 & 6 & 11 & & \\
\hline CP4 & 7 & 9 & 19 & & \\
\hline CP5 & 9 & 18 & 28 & & \\
\hline CP6 & 6 & 16 & 25 & & \\
\hline CP7 & 6 & 14 & 14 & & \\
\hline CP8 & 5 & 11 & 14 & & \\
\hline CP9 & 4 & 10 & 10 & 32 & \\
\hline CP10 & 9 & 14 & 22 & 32 & \\
\hline CP11 & 5 & 11 & 18 & 32 & \\
\hline CP12 & 4 & 11 & 22 & 30 & \\
\hline CP13 & 4 & 12 & 5 & 5 & \\
\hline CP14 & 3 & 10 & 10 & 11 & 10 \\
\hline
\end{tabular}

Tabela 1 - Médias de contagens de parasitos em 30 campos diferentes de $400 \times$ em cada animal. 
A inoculação foi feita por via intraperitoneal com $0,1 \mathrm{ml}$ de sangue citratado, obtido por punção cardiaca de outros camundongos parașitados com T. cruzi. Foi usada a cepa " $Y$ " mantida no Departamento de Patologia da Faculdade de Medicina de Ribeirão Prêto, cujos animais foram submetidos prèviamente ao exame parasitêmico, colocando-se, entre lâmina e lamínula, uma gôta de sangue extraído por punção da cauda do animal. A parasitemia revelou, em todos os casos, 20 a 25 parasitos em média por campo de $400 \times$, obtida por contagem de 30 campos diferentes (tabela 1).

A parasitemia dos animais inoculados foi verificada diăriamente a partir do 5o dia de inoculação, segundo a técnica descrita. Os valôres correspondentes constam da tabela 1.

Foram aproveitados os animais que morreram ou foram sacrificados entre 0 $7^{\circ}$ e $9^{\circ}$ dias após a inoculaçāo. Os animais foram observados cada 2 horas a partir do $5^{*}$ dia após a inoculaçāo, a fim de que, em caso de morte, não houvesse demora na fixação do material, evitando a lise do sistema nervoso central. Os animais só foram sacrificados quando apresentavam quadros agônicos, caracterizados por grande prostração e por paralisias de segmentos corporais.

Os cerebelos foram retirados em bloco com o cérebro e fixados imediatamente em formol a $10 \%$.

Antes de proceder ao estudo do material, verificamos o tamanho médio das células de Purkinje no camundongo, a fim de determinar a espessura dos cortes que deveriam ser usados, evitando que uma mesma célula fôsse contada mais de uma vez em cortes histológicos sucessivos. Para essa verificação usamos a câmara de Spencer, realizando medidas celulares em 5 camundongos normais. Encontramos os valôres citados na tabela 2 .

\begin{tabular}{|c|c|c|c|c|c|c|c|c|c|}
\hline \multicolumn{2}{|c|}{$C N 1$} & \multicolumn{2}{|c|}{$C N 2$} & \multicolumn{2}{|c|}{ CNB } & \multicolumn{2}{|c|}{$\mathrm{CN}_{4}$} & \multicolumn{2}{|c|}{ CN5 } \\
\hline$N^{o}$ & Valôres & $N^{o}$ & Valôres & No & Valôres & $N^{o}$ & Valôres & $N^{o}$ & Valôres \\
\hline 1 & 13,32 & 1 & 12,21 & 1 & 8,88 & 1 & 10,43 & 1 & 12,21 \\
\hline 2 & 15,32 & 2 & 13,76 & 2 & 8,88 & 2 & 11,10 & 2 & 10,88 \\
\hline 3 & 13,32 & 3 & 10,88 & 3 & 13,32 & 3 & 12,65 & 3 & 12,44 \\
\hline 4 & 12,44 & 4 & 13,54 & 4 & 10,43 & 4 & 12,21 & 4 & 11,77 \\
\hline 5 & 13,32 & 5 & 15,32 & 5 & 13,54 & 5 & 13,54 & 5 & 11,99 \\
\hline 6 & 12,44 & 6 & 13,32 & 6 & 11,54 & 6 & 11,10 & 6 & 13,32 \\
\hline 7 & 15,10 & 7 & 11,77 & 7 & 8,88 & 7 & 8,88 & 7 & 12,65 \\
\hline 8 & 11,99 & 8 & 13,54 & 8 & 9,99 & 8 & 9,99 & 8 & 12,88 \\
\hline 9 & 11,99 & 9 & 12,21 & 9 & 12,88 & 9 & 11,99 & 9 & 11,77 \\
\hline 10 & 13,76 & 10 & 11,10 & 10 & 9,10 & 10 & 9,10 & 10 & 12,65 \\
\hline
\end{tabular}

Total: 605,64

Média: 12,11 micra

Tabela 2 - Medidas das células de Purkinje em 5 camundongos normais.

Baseados nesse valor médio, fizemos cortes seriados de 8 micra de espessura, estudando cada terceiro corte. Obtivemos cêrca de 90 cortes para cada animal.

O método de coloraçāo empregado foi o da hematoxilina-eosina, satisfatório para o estudo quantitativo, segundo a experiência de Köberle e colaboradores.

As contagens foram feitas em 200 campos diferentes de $400 \times$, tomados indiscriminadamente para cada cerebelo de animal normal ou portador de tripanosomiase; contudo as contagens foram sempre efetuadas no segmento linear das fôlhas cerebelares. Foram examinados 4.800 campos, e contadas 60.718 células. Nessa 
contagem foram incluidas tôdas as células de Purkinje ainda presentes, mesmo aquelas que mostravam alterações evidentes de sua estrutura.

No tratamento estatístico dos resultados, calculamos os limites de normalidade para o número de neurônios contados em cada grupo observado, usando uma estimativa do desvio padrão das médias dos neurônios dos camundongos normais, baseada no cálculo da variância entre os camundongos, obtida mediante análise de variância.

Verificamos, assim, que o limite inferior do intervalo da normalidade é de 14,4 neurônios por campo de $400 \times$.

As médias neuronais obtidas na observaçāo do grupo patológico constam da tabela 3, onde podemos verificar que, dos 14 animais parasitados, apenas dois não mostraram diminuiçāo da média de neurônios por campo contado, e que os 12 restantes apresentaram reduçāo, que variou de 8,8 a 11,6 , correspondendo dessa maneira a $85,7 \%$ de alterações. A tabela 4 mostra os números totais das contagens individuais e as médias neuronais correspondentes a cada animal normal. A comparação das tabelas 3 e 4 demonstra que a análise estatística dos resultados nos autoriza a afirmar que, durante a fase aguda da moléstia de Chagas experimental no camundongo, há redução significativa do número de células de Purkinje.

\begin{tabular}{llr||lrr}
\hline Animal & Total & Média & Animal & Total & Média \\
\hline CP1 & 2. C58 & 10,3 & CP8 & 1.933 & 9,7 \\
CP2 & 1.751 & 8,8 & CP9 & 1.695 & 8,5 \\
CP3 & 1.851 & 9,3 & CP10 & 1.825 & 9,1 \\
CP4 & 2.912 & 14,6 & CP11 & 2.886 & 14,4 \\
CP5 & 2.315 & 11,6 & CP12 & 2.086 & 10,4 \\
CP6 & 2.138 & 10,7 & CP13 & 1.863 & 9,3 \\
CP7 & 1.859 & 9,3 & CP14 & 1.776 & 8,9 \\
\hline
\end{tabular}

Tabela 3 - Número total e número médio de neurônios contados por campo em 14 animais parasitados.

\begin{tabular}{|c|c|c|c|c|c|}
\hline Animal & Total & Média & Animal & Total & Média \\
\hline CN1 & 3.297 & 16,4 & CN6 & 3.120 & 15,6 \\
\hline $\mathrm{CN} 2$ & 3.390 & 16,9 & CN7 & 3.118 & 16,5 \\
\hline CN3 & 3.207 & 16,0 & CN8 & $2 . \$ 99$ & 14,9 \\
\hline CN4 & 3.345 & 16,7 & CNS & 3.126 & 15,6 \\
\hline CN5 & 3.117 & 15,5 & CN10 & 3.051 & 15,2 \\
\hline
\end{tabular}

Tabela 4 - Nímero total e número médio de neurônios contados por campo em 10 animais normais.

\section{RESULTADOS}

Nossos resultados demonstram que as alterações quantitativas das células de Purkinje, durante a fase aguda da moléstia de Chagas experimental no camundongo, sāo bastante evidentes. Dos 14 animais que morreram ou foram sacrificados entre o $7^{\circ}$ e $9^{\circ}$ dias após a inoculação, 12 (ou seja 85,7\%) mostraram diminuição do número de neurônios, compreendida entre os limites de 1.695 e 2.315 cé- 
Lulas, com médias de 8,5 a 11,6 neurônios por campo, os dois animais restantes mostraram valôres que correspondem ao limite inferior do intervalo de normalidade, isto é, de 2.886 e 2.912 neurônios, com médias de 14,4 e 14,6.

No grupo normal as variações foram de 2.999 a 3.390 células, com médias de 14,9 a 16,9. A média dos valôres obtidos para os 12 animais do grupo patológico com alterações quantitativas significantes foi de 1.962 neurônios, ao passo que no grupo contrôle esta média foi de 3.177. A comparação dêstes dois valôres revela que houve uma redução de $38,3 \%$ dos neurônios no grupo patológico, resultado que é concordante com trabalhos sôbre redução quantitativa neuronal, realizados por Alcântara, Köberle, Brandão, Schwartzburd e Köberle, Penha e G. Köberle.

As alteraçōes quantitativas no grupo patológico nāo foram, porém, constantes em todos os campos examinados. Um dos animais (CP 10) apresentou diminuição dos neurônios em todos os campos, ao passo que 11 animais $(1,2,3,5,6,7,8,9,12$, 13 e 14) sofreram essa diminuição na maior parte dos campos examinados, porém, com áreas de população neuronal aparentemente normal.

\begin{tabular}{lcccccc}
\hline & $\begin{array}{c}\text { Valôres inferiores } \\
\text { ao intervalo de } \\
\text { normalidade }\end{array}$ & $\begin{array}{c}\text { Valôres iguais ao } \\
\text { intervalo de } \\
\text { normalidade }\end{array}$ & $\begin{array}{c}\text { Valôres superiores } \\
\text { ao intervalo de } \\
\text { normalidade }\end{array}$ \\
\cline { 2 - 7 } & No & $\%$ & $N^{\circ}$ & $\%$ & No & $\%$ \\
\hline \hline Grupo normal & 644 & 32,0 & 855 & 43,0 & 501 & 25,0 \\
Grupo patológico & 2423 & 85,1 & 164 & 5,9 & 113 & 4,0 \\
Grupo patológico exceto & 2224 & 92,7 & 144 & 6,0 & 31 & 1,3 \\
$\quad \begin{array}{l}\text { CP4 e CP11 } \\
\text { Animais CP4 e CP11 }\end{array}$ & 199 & 49,7 & 120 & 30,0 & 82 & 20,3 \\
\hline
\end{tabular}

Tabela 5 - Freqüência dos valôres encontrados nas contagens, em relaçāo ao intervalo de normalidade

Assim, analisando-se a freqüência dos valôres encontrados nas contagens e considerando-se o intervalo de no:malidade, os valôres inferiores e superiores a êste intervalo constam da tabela 5 .

Nesta última, observamos que no grupo patológico os campos com redução de neurônios corresponderam a $85,1 \%$ do total; os campos com valôres incidindo dentro dos limites do intervalo de normalidade corresponderam a $5,9 \%$ do total e que os campos com valôres mais elevados que o limite superior do intervalo de normalidade corresponderam a $4 \%$.

\section{COMENTARIOS}

A diminuição de neurônios por campo, em cada animal, não foi constante, excetuados CP4 e CP11, nos quais essa redução se verificou na maioria dos campos examinados. Contudo, alguns dos campos estudados apresentavam valôres normais. Isto nos permite deduzir que as alterações das células de Purkinje não ocorrem com a mesma intensidade em todo o córtex cerebelar.

Observamos, durante as contagens, a presença de pseudocistos e de leishmânias esparsas no córtex cerebelar em alguns animais. As regiōes adja- 
centes a estas zonas mostraram alterações morfológicas celulares pronunciadas. Tal fato já foi assinalado por Köberle em 1959 e está documentado nas figuras que se seguem ao texto.

Os animais CP4 e CP11 não evidenciaram alterações significativas. Os valôres encontrados são semelhantes àqueles obtidos para o grupo contrôle. Este achado não parece constituir fato excepcional, pois o próprio Chagas ${ }^{5}$, em 1916, achava razoável "admitir que a substância nervosa não constitui de modo constante, ou pelo menos com a constância do miocárdio, sede de multiplicação do tripanosoma".

Como foi dito anteriormente, incluímos nas contagens tôda e qualquer célula de Purkinje que conseguimos identificar em cada campo independentemente do grau de alterações que apresentasse. As alterações morfológicas celulares que observamos nos animais patológicos foram de tal modo intensas que nos parece lícito admitir que, se houvesse sobrevivência à fase aguda, um estudo histopatológico posterior provàvelmente deveria mostrar muito maiores destruições neuronais que as encontradas.

O mecanismo intrínseco desta destruição é ainda desconhecido. Chagas 5, em 1916, já suspeitava da presença de uma substância tóxica para a célula nervosa; Torres ${ }^{12}$, em 1941, dizia que o "processo inflamatório na doença de Chagas é, pois, a conseqüência de uma ação induzida à distância pelo S. cruzi por meio de uma hipotética noxina esquizotripânica". Alvarenga ${ }^{2}$, em 1959, estudando * camundongos infectados experimentalmente, aventou a hipótese da existência de uma toxina liberada ao nível dos tecidos parasitados, e "capaz de lesar qualquer tipo de tecido".

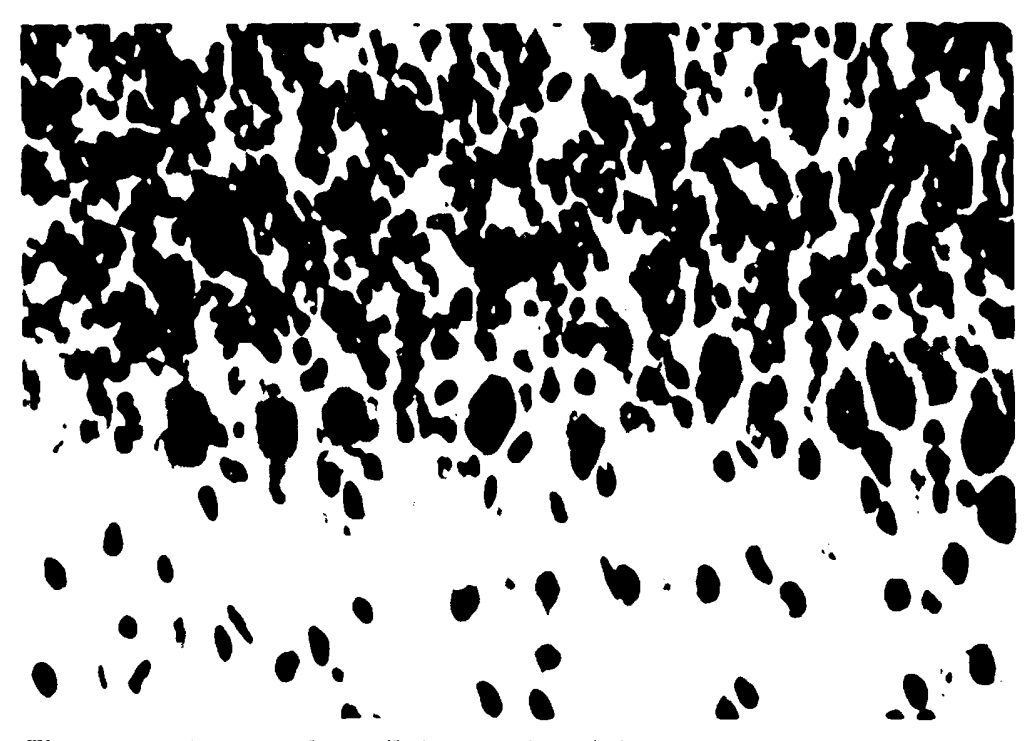

Fig. 1 - Aspecto das células de Purkinje em camundongo normal. Animal CN1. (Hematoxilina-eosina, 1600×). 


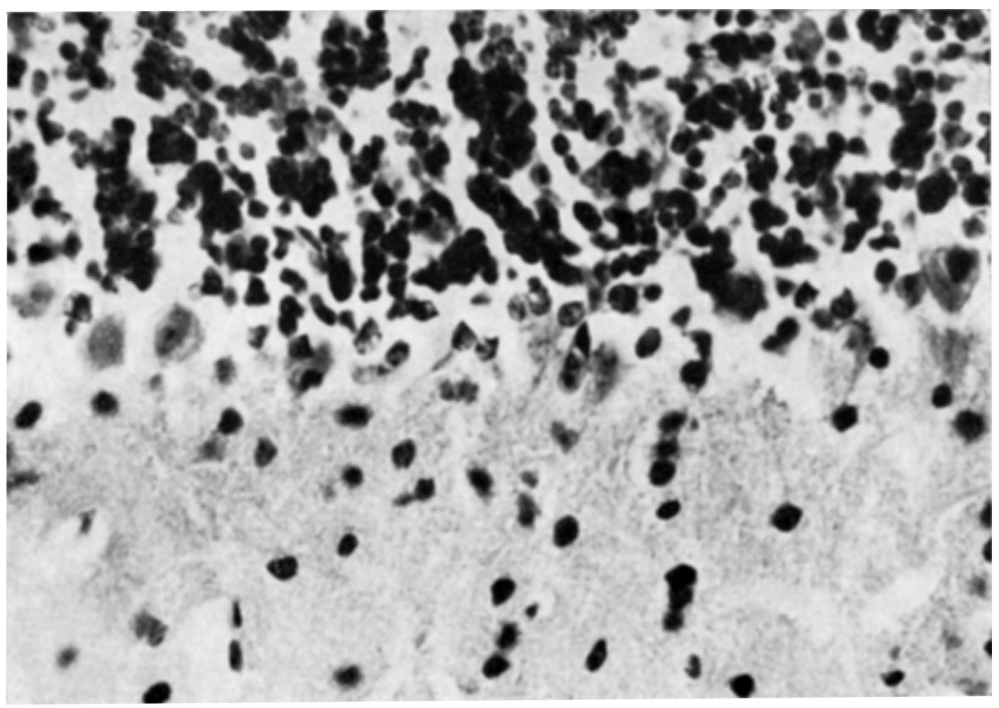

Fig. 2 - Intensa destruição das células de Purkinje em camundongo chagásico. Animal CP13. (Hematoxilina-eosina, 1600×).

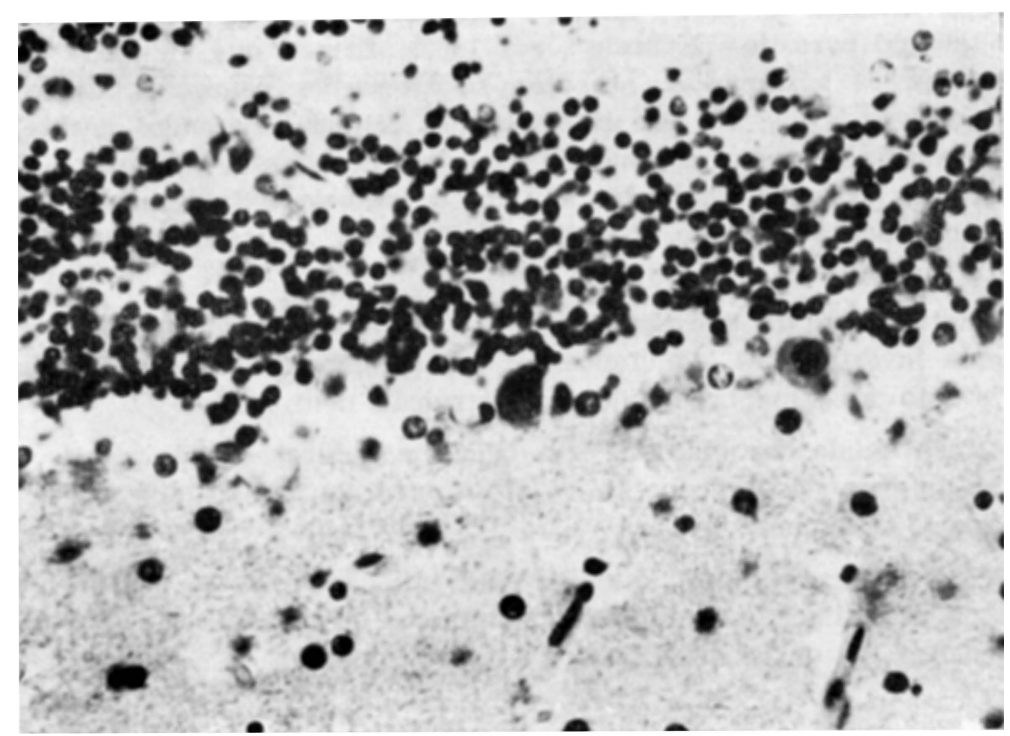

Fig. 3 - Aspecto do córtex cerebelar em camundongo chagásico, mostrando a destruição intensa das células de Purkinje. Animal CP2. (Hematoxilina-eosina, $1600 \times)$. 


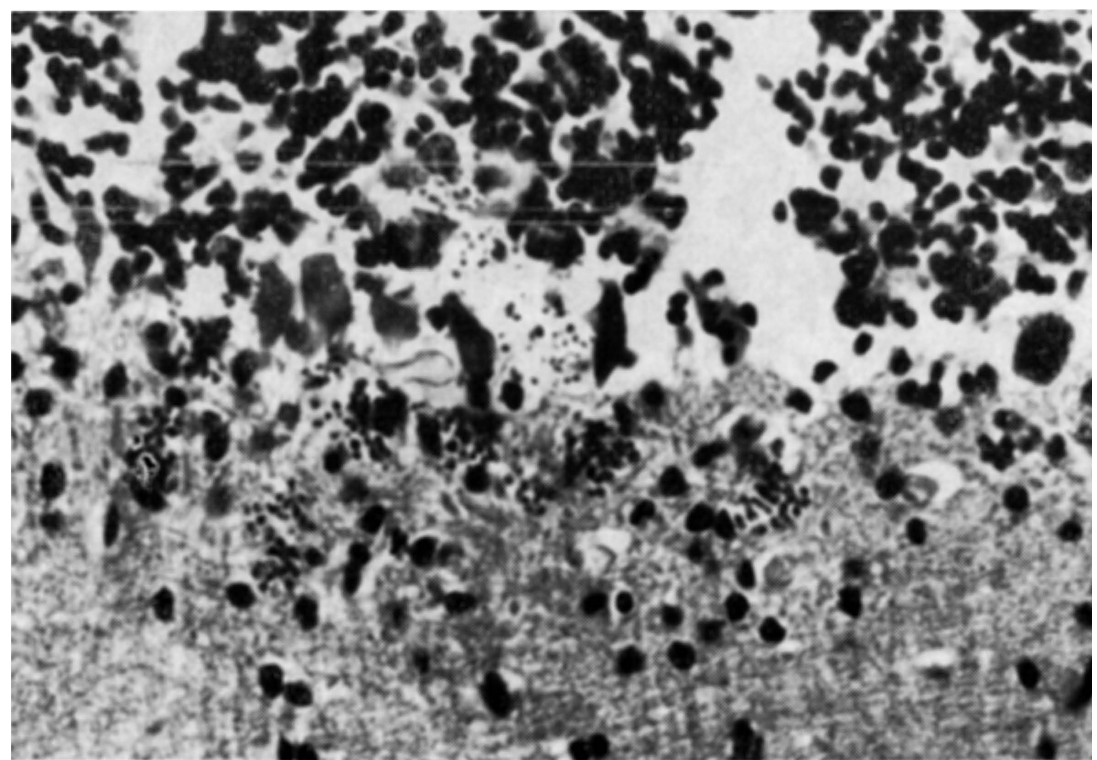

Fig. 4 - Ninhos de leishmânia no córtex cerebelar. Animal CP9. (Hematoxilina-eosina, $1600 \times$ ).

Köberle e Alcântara 9, em 1960, sugeriram que a destruição das células se dá à custa de uma "toxina", liberada por destruição de formas em leishmânia do parasito. Köberle ${ }^{8}$, em 1962, afirmou que "à medida que se desintegram as leishmânias, observam-se altèraçōes neuronais, desde lesões nucleocitoplasmáticas, até lise completa das células. Baseados nestas observações, somos forçados a concluir que, na ocasião da desintegração das leishmânias, ocorre a liberação de uma substância extremamente deletéria para o neurônio. Segundo a nossa opinião deve tratar-se de uma endotoxina (neurotoxina)".

A natureza desta substância neurotóxica é, ainda, questão pendente de ulteriores investigações bioquímicas, e, na opinião d€ Köberle ${ }^{8}$, secundária, pois "o fato fundamental reside na destruição neuronal".

A fase aguda, no material estudado, teve duração máxima de 9 dias. Dos 14 animais dêsse grupo, $6(43 \%)$ morreram no $7 .^{\circ}$ dia, $7(50 \%)$ no $8 .^{\circ}$ dia e $1(7 \%)$ no $9 .^{\circ}$ dia.

Não nos pareceu, pois, que houvesse relação entre a duração da fase aguda da moléstia e a diminuição do número de neurônios, cuja explicação talveż esteja na curta duração desta fase.

\section{CONCLUSOES}

1) Na fase aguda da moléstia de Chagas experimental no camundongo, há redução do número đe células de Purkinje, estatìsticamente significativa; 
2) dos 14 animais estudados, 12 apresentaram diminuição neuronal; 3) as reduções neuronais na maior parte dos animais estudados se apresentaram alternadas com áreas de população neuronal aparentemente normal; 4) nas regiões onde haviam leishmânias no interior de pseudocistos ou esparsas nos tecidos, constatamos alterações morfológicas neuronais intensas; 5) não nos pareceu que houvesse relação entre a duração da fase aguda e a redução do número de neurônios.

\section{RESUMO}

O autor estudou quantitativamente as células de Purkinje em cortes semi-seriados do cerebelo de camundongos inoculados experimentalmente com T. cruzi, tendo verificado considerável destruição neuronal na fase aguda da enfermidade.

\section{SUMMARY}

Quantitative study of Purkinje cells in the acute phase of experimental Chagas' disease

A quantitative study of Purkinje cells was done through semi-serial sections of cerebellum of mice experimentally innoculated by Trypanosoma cruzi. A very marked neuronal destruction was found in the acute phase of Chagas' disease.

\section{REFERENCIAS}

1. AlCantara, F. G. - Sistema neurovegetativo do coração na moléstia de Chagas experimental. Tese de doutoramento, Faculdade de Medicina de Ribeirão Prêto, 1959.

2. Al.VARENGA, R. J. - Histopatologia da fase aguda da moléstia de Chagas em camundongos. I Congresso Internacional sôbre a Moléstia de Chagas, Rio de Janeiro, 1959.

3. BRANDAO, H. J. S. - Estudo quantitativo de neurônios simpáticos e parassimpáticos na moléstia de Chagas experimental em ratos. Tese de doutoramento, Faculdade de Medicina de Ribeirão Prêto, 1961.

4. CHAGAS, C. - Les formes nerveuses d'une nouvelle Trypanosomiase. Trypanosoma cruzi inoculé par Triatoma megista (maladie de Chagas). Nouv. Iconogr. Salpêtrière 26(1):1-19, 1913.

5. ChaGAS, C. - Processos patogênicos da tripanosomiase americana. Mem. Inst. Oswaldo Cruz, Rio 8(2):5-36, 1916.

6. KOBERLE, F. - El mal de Chagas. Enfermedad del sistema nervioso. Rev. Med. Córdoba $47(2): 1 C 5-133,1959$. 
7. KOBERLE, F. - Estudos quantitativos da destruição neuronal na moléstia de Chagas. IV Reunião da Associação Latino-Americana de Ciências Fisiológicas, Ribeirão Préto, 1961.

8. KOBERLE, F. - Patologia da moléstia de chagas. Medicina CARL, Ribeirão Prêto $1(2): 73-98,1962$.

9. KOBERLE, F. \& ALCANTARA, F. G. - Mecanismo da destruição neuronal do sistema nervoso periférico na moléstia de Chagas. Hospital 57(6):173178,1960

10. PENHA, Fo, P. D. \& KOBERLE, G. - Megaesôfago chagásico. Estudo quantitativo do plexo de Auerbach. Rev. Goiana Med. 5:185-192, 1959.

11. SCHWARTZBURD, H. \& KOBERLE, F. - Chagas-Myelopathie. Zschr. f. Tropenmed. u. Parast. 10:309-314, 1959.

12. TORRES, C. M. - Sôbre a anatomia patológica da doença de Chagas. Mem. Inst. Oswaldo Cruz 36(3):391-404, 1941.

Departamento de Neurologia - Faculdade de Medicina - Caixa Postal $\$ 01$ - Ribeirão Prêto, SP - Brasil. 